\title{
RESEÑA DEL LIBRO: "MIRADAS LÚDICAS" de María Regina Öfele, Editorial Dunken, Buenos Aires, 2004
}

\author{
Flora Eugenia Salas Madriz \\ Escuela de Administración Educativa, Facultad de Educación \\ Universidad de Costa Rica
}

Recibido 28-XI-2008 • Aceptado 7-XII-2008 • Corregido 12-XII-2009

María Regina Öfele obtuvo una maestría y un doctorado en Psicología Educativa en Estados Unidos y ha dedicado gran parte de su carrera de más de 15 años como profesora titular de la Facultad de Educación de la Universidad de San Pablo (Argentina) a estudiar el juego y sus implicaciones en el campo de la Educación y la Clínica Psicopedagógica. Actualmente, es directora del Instituto de Investigación y Formación en Juego, a cuya página web (http://www.instituto.ws/iifj/esp/cap00. htm) se puede acceder para obtener mayor información sobre este libro. Sus tesis de maestría y doctorado también versaron sobre el tema del juego. Ha publicado otros estudios relacionados:

1. Infancia y juego -aspectos históricos

2. Los juegos tradicionales y sus proyecciones pedagógicas

3. Niños en riesgo

4. Jugar y aprender en el marco de la clínica psicopedagógica

5. Jugar en tiempos de crisis

6. Papel social de los juegos tradicionales
Miradas lúdicas es producto de la revisión teórica y la investigación del juego vinculado a la Educación y a la Clínica Psicopedagógica, por lo que constituye un aporte fundamental para docentes, psicopedagogos(as) e investigadores(as) en el campo. El libro consta de ocho capítulos y presenta una extensa bibliografía especializada, lo que orienta a quienes están interesados en el uso del juego como herramienta pedagógica. Trata de manera sencilla, pero fundamentada y muy bien documentada, temas como: la observación del juego, métodos y hallazgos de investigación, las relaciones entre el juego y el aprendizaje, el juego y las instituciones educativas, la promoción y la transgresión del juego, juego y cultura, y el juego y sus aplicaciones en la clínica psicopedagógica.

Expone teorías y aplicaciones del juego en la educación, así como las relaciones entre juego y aprendizaje. El capítulo III, titulado ¿Aprender y jugar o jugar aprendiendo?, es de especial interés para el campo de la Educación, ya que esclarece a nivel teórico y práctico cuándo se está frente a una actividad lúdica o no, y las diferencias entre 
el juego espontáneo, el juego libre y el juego como medio para propiciar aprendizajes en el sistema escolar.

Otro tema de especial interés es el análisis que hace Öfele en el capítulo IV, titulado El juego y las instituciones educativas, porque examina las condiciones mínimas que se deben dar en las escuelas para que el juego realmente se integre como un elemento que favorezca el aprendizaje, el desarrollo motor, psicoafectivo, social, cultural, lingüístico y la creatividad.
En 150 páginas, la autora proporciona un claro y fundamentado recorrido sobre el juego como actividad humana esencial y compleja, cuyas implicaciones y aplicaciones para la educación apenas se empiezan a comprender. Por ello, considero que este libro ofrece un punto de partida para quienes se interesan por el tema del juego en la educación, que gana interés en Costa Rica y empieza a ser estudiado con mayor profundidad y detenimiento, especialmente en preescolar y primaria. 